\title{
PENGAMATAN ASPEK BIOLOGI REPRODUKSI IKAN KAKAP MERAH (Lutjanus malabaricus) DARI PERAIRAN SAPE DAN KUPANG
}

\author{
Retno Andamari"), David Milton ${ }^{* *}$, Tonya Van der Velde, " ${ }^{* *}$ dan Bambang Sumiono ${ }^{* * *}$ )
}

\begin{abstract}
ABSTRAK
Pengamatan aspek biologi reproduksi ikan kakap merah (Lutjanus malabaricus) dari perairan Sape dan Kupang telah dilakukan pada sampel ikan yang diambil setiap bulan mulai Desember 2000 sampai dengan Nopember 2001 di perairan Sape dan Januari sampai Desember 2001 di perairan Kupang. Analisis yang dilakukan meliputi hubungan panjang berat, tingkat kematangan gonad, indeks kematangan gonad, fekunditas, dan diameter telur pada ikan kakap merah sebanyak 389 ekor dari Sape dan 350 ekor dari Kupang. Hubungan panjang berat di kedua lokasi tersebut mempunyai nilai $b<3$ (berdasarkan uji t) berarti spesies ikan kakap ini mempunyai pertumbuhan alometrik negatip. Ikan kakap merah memiliki sifat memijah berganda dan mempunyai fekunditas rata-rata di Sape 316.401 butir dan 423.130 butir di Kupang. Diameter oosit berkisar antara $500 \mu \mathrm{m}$ sampai $600 \mu \mathrm{m}$ baik di Sape maupun di Kupang. Ikan kakap merah memijah hampir terjadi sepanjang tahun dengan musim pemijahan pada bulan Januari sampai Maret.
\end{abstract}

ABSTRACT: Obsenvation on reproductive biology of red snapper (Lutjanus malabaricus) from Sape and Kupang waters. By: Retno Andamari, David Milton, Tonya Van der Velde, and Bambang Sumiono

Studies on the reproductive biology of red snapper (Lutjanus malabaricus) were carried out in Sape and Kupang waters. Sampling was conducted from December 2000 to November 2001 in Sape waters and January to December 2001 in Kupang. Length-weight relationships, gonad maturity stage, gonadosomatic index (GSI), fecundity and egg diameter were examined from 389 fish from Sape and 350 fish from Kupang. The constant (b) of length-weight relationship for both areas is less than 3 (t-test) suggesting this species to have negative allometric growth. Lutjanus malabaricus is a multiple spawner with an average batch fecundity 316, 401 in Sape and 423,130 in Kupang. The oocyte diameter were between 500 um to 600 $\mu \mathrm{m}$ both in Sape and Kupang. Spawning occurs throughout the year with the peak season during January to March.

KEYWORDS: $\quad$ red snapper, length-weight, GSI, fecundity

\section{PENDAHULUAN}

Ikan kakap merah merupakan salah satu ikan demersal yang mempunyai arti penting dalam perikanan trawl dan "drop" line di Indonesia. Ikan ini juga merupakan salah satu komoditas ekspor. Perikanan kakap merah juga merupakan sumber utama pemanfaatan tenaga kerja, pemenuhan kebutuhan sumber protein hewani dan sebagai sumber devisa negara. Menurut Suboko (1997) total ekspor ikan kakap merah di Indonesia menurun dari 53.000 ton pada tahun 1995 menjadi 6.000 ton pada tahun 1994. Lutjanus malabaricus termasuk salah satu dari kelompok ikan kakap merah yang ada di perairan Indonesia. Ikan ini biasa ditangkap dengan rawai dasar atau trawl yang menurut informasi dari beberapa perusahaan penangkapan cenderung menurun hasilnya dari tahun ke tahun. Menurut Newman et al. (2000) ikan kakap merah jenis $L$. malabaricus mempunyai umur yang cukup panjang dapat mencapai 20 tahun dan pertumbuhannya relatif lambat setelah mencapai dewasa (mampu bereproduksi). Musim pemijahan ikan kakap merah di Great Barrier Reef berlangsung pada bulan Oktober sampai dengan Januari (McPaerson, et al., 1992). Di Indonesia belum banyak dilakukan penelitian tentang musim pemijahan ikan kakap merah khususnya $L$. malabaricus. Untuk menjaga kesinambungan hasil tangkapan perlu diketahui salah satunya adalah aspek biologi reproduksi dari ikan kakap merah ini.

Penelitian ini dilakukan di Sape dan Kupang dengan tujuan untuk mengetahui hubungan panjang berat ikan kakap merah, tingkat kematangan gonad, indeks kematangan gonad, musim pemijahan, fekunditas dan diameter telur. Dengan diketahuinya parameter tersebut diharapkan dapat memberikan informasi sebagai salah satu masukan bagi pengelolaan sumber daya ikan kakap merah.

\section{BAHAN DAN METODE}

\section{Pengambilan Contoh}

Pengambilan contoh ikan kakap merah (Lutjanus malabaricus) dila'iukan di tempat pendaratan ikan di Sape dan Kupang setiap bulan selama satu tahun. Sampling tersebut dilaksanakan pada bulan Desember 2000 sampai November 2001 di Sape dan Januari sampai Desember 2001 di Kupang. Ikan kakap merah (Gambar 1) sebanyak 30 ekor masing-

\footnotetext{
-) Peneliti pada Balai Besar Riset Perikanan Budidaya Laut Gondol, Sing araja

*) Peneliti pada CSIRO Marine Research, Cleveland

- Peneliti pada Balai Riset Perikanan Laut, Jakarta
} 


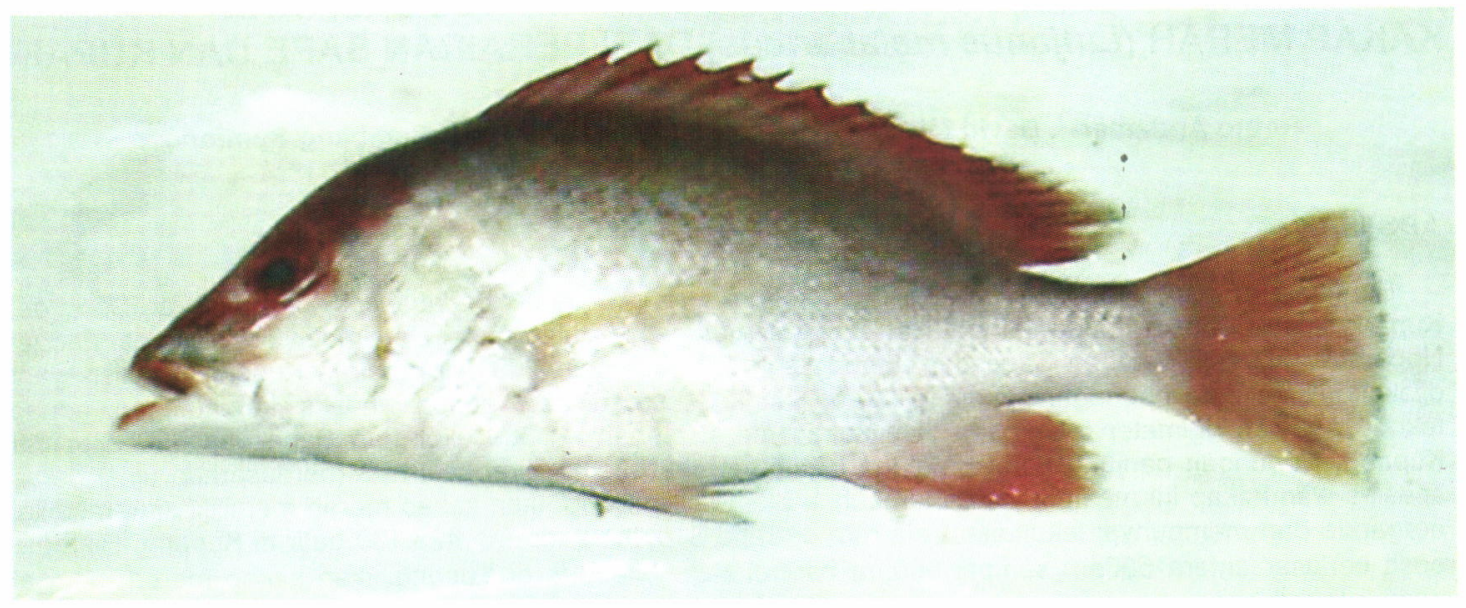

Gambar 1. Ikan kakap merah (Lutjanus malabaricus).

Figure 1. Scarlet snapper (Lutjanus malabaricus).

masing di Sape dan Kupang diambil setiap bulan. Identifikasi ikan kakap merah berdasarkan Allen (1985) dan Sainsbury et al. (1985). Ikan tersebut diukur panjang total dan panjang standar $(\mathrm{mm})$, berat (gram) dan dibedah untuk diambil gonadnya. Semua sampel gonad diawet dengan formalin 10\%. Analisa gonad dilakukan di laboratorium Balai Besar Riset Perikanan Budidaya Laut Gondol.

\section{Analisa Laboratorium}

Gonad tersebut ditimbang (dengan ketelitian 0,001 mg) sebelum dibuat preparat histologis untuk pengamatan tingkat kematangannya. Pembuatan preparat histologis menurut Luna (1986). Preparat diiris setebal 6 mikron dan diberi pewarnaan dengan Hematoxylen-Eosyn. Penentuan Tingkat Kematangan Gonad dilakukan berdasarkan Milton dan Blaber (1991); Andamari et. al., (1998) dapat dilihat pada Tabel 1.

\section{Analisa Data}

Hubungan panjang berat ditentukan dengan rumus (Royce, 1985)

$$
W=a L^{b}
$$

di mana:

$$
\begin{aligned}
W & =\text { berat }(\text { gram }) \\
\mathrm{L} & =\text { panjang }(\mathrm{mm}) \\
\mathrm{a}, \mathrm{b} & =\text { konstanta }
\end{aligned}
$$

Apabila $b>3$ bersifat alometrik positip dan $b<3$ disebut alometrik negatip.

Untuk menentukan Indeks Kematangan Gonads (IKG) menggunakan rumus menurut Effendie (1997).

$$
\text { IKG }=\underline{W}-\mathbf{W g} \times 100 \%
$$

$$
\text { di mana: }
$$

$\mathrm{W}=$ berat ikan (gram)

$\mathrm{Wg}=$ berat gonad (gram)

Fekunditas total diduga dengan cara menimbang sub-sampel gonad dari gonad tingkat $V$ dan tidak terdapat tingkat VI kemudian dihitung jumlahnya (Bagenal, 1978). Fekunditas total diduga berdasarkan persamaan:

$$
\mathrm{F}=(\mathrm{Wg} / \mathrm{Ws}) \mathrm{n}
$$

di mana:

$$
\begin{aligned}
& \mathrm{F}=\text { fekunditas total } \\
& \mathrm{Wg}=\text { berat gonad }(\mathrm{gr}) \\
& \mathrm{Ws}=\text { berat gonad sub sampel }(\mathrm{gr}) \\
& \mathrm{N}=\text { jumlah telur dalam sub sampel }
\end{aligned}
$$

Tabel 1. Kriteria yang digunakan untuk menentukan tingkat kematangan gonad ikan kakap merah (Lutjanus malabaricus)

Table 1. Criteria used for staging female gonads of Lutjanus malabaricus

\begin{tabular}{cll}
\hline Tingkat & \multicolumn{1}{c}{ Keterangan } & \multicolumn{1}{c}{ Histologi } \\
\hline 1 & Tidak masak (immature) & Terdapat oogonia (Oogonia present) \\
2 & Perkembangan (developing/resting) & Pre-vitellogenic oocytes \\
3 & Pemasakan (maturing) & Yolk precursor stage; some non-staining yolk \\
4 & Matang (Ripe) & Non-staining yolk; developed chorion \\
5 & Reproduksi (Running ripe) & Homogeneous red staining yolk; oocytes hydrated; \\
& & Atresia dan previtellogenik oosit \\
6 & Salin (Spent) & Terdapat post-vitellognic follicles \\
\hline
\end{tabular}




\section{HASIL DAN BAHASAN}

\section{Hubungan Panjang-Berat}

Diskripsi panjang dan berat ikan contoh berdasarkan jenis kelamin disajikan pada Tabel 3,4 dan 5 . Hubungan panjang berat ikan kakap merah yang digabung dalam satu tahun di Sape ditunjukkan oleh persamaan $W=0,0001 L^{2,7423}$ dengan koefisien korelasi 0,98 . Untuk ikan yang berasal dari Kupang diperoleh persamaan $W=0,0001 L^{2,7165}$ dengan koefisien korelasi 0,99. Berdasarkan uji $t$ dari persamaan tersebut terlihat bahwa nilai b lebih kecil

Tabel 2. Hubungan panjang berat $\left(W=a L^{b}\right)$ ikan kakap merah (L. malabaricus) berdasarkan jenis kelamin di Kupang pada bulan Januari sampai dengan Desember 2001 dan di Sape pada bulan Desember 2000 sampai dengan Nopember 2001

Tabe/2. Length-weight relationship of L. malabaricus based on sex from Kupang in January to December 2001 and from Sape in November 2000 to December 2001

\begin{tabular}{lcccc}
\hline \multicolumn{1}{c}{ Location/sex } & $\mathbf{N}$ & $\mathbf{a}$ & $\mathbf{B}$ & $\mathbf{R}^{\mathbf{2}}$ \\
\hline Kupang & & & & \\
Female & 193 & 0,0001 & 2,71 & 0,97 \\
Male & 137 & 0,0001 & 2,77 & 0,98 \\
Unidentified & 18 & 0,0002 & 2,62 & 0,97 \\
Sape & & & & \\
Female & 167 & 0,0001 & 2,73 & 0,96 \\
Male & 121 & 0,0002 & 2,68 & 0,95 \\
Unidentified & 103 & 0,0001 & 2,74 & 0,95 \\
\hline
\end{tabular}

Tabel 3. Rata-rata, kisaran panjang standard $(\mathrm{mm})$, dan berat $(\mathrm{g})$ ikan kakap merah betina di Sape dan Kupang pada bulan Desember 2000 sampai dengan bulan Desember 2001

Table 3. The mean and range in length $(\mathrm{mm})$ and weight $(\mathrm{g})$ of female red snapper (L. malabaricus) collected from Sape between December 2000 and December 2001

\begin{tabular}{|c|c|c|c|c|c|c|c|c|}
\hline \multirow{2}{*}{ LOCATION } & \multirow{2}{*}{ MONTH } & \multicolumn{4}{|c|}{ Standard Length $(\mathrm{mm})$} & \multicolumn{3}{|c|}{ Weight (g) } \\
\hline & & $\mathbf{n}$ & Min & Max & Mean \pm SE & Min & $\operatorname{Max}$ & Mean \pm SE \\
\hline Sape & Dec-00 & 16 & 323 & 405 & $365,56 \pm 5,42$ & 990 & 1600 & $1335,31 \pm 46,95$ \\
\hline Sape & \multirow{2}{*}{ Jan-01 } & 9 & 250 & 630 & $411,67 \pm 42,59$ & 460 & 4900 & $2088,89 \pm 509,74$ \\
\hline Kupang & & 19 & 462 & 536 & $500,74 \pm 5,74$ & 2450 & 3750 & $3145,26 \pm 77,34$ \\
\hline Sape & \multirow{2}{*}{ Feb-01 } & 14 & 260 & 553 & $448,36 \pm 23,63$ & 700 & 4390 & $2667,14 \pm 324,68$ \\
\hline Kupang & & 23 & 465 & 557 & $505,87 \pm 4,92$ & 2400 & 3600 & $3038,04 \pm 73,75$ \\
\hline Sape & \multirow{2}{*}{ Mar-01 } & 12 & 380 & 550 & $425,50 \pm 14,70$ & 1600 & 3850 & $2183,33 \pm 246,90$ \\
\hline Kupang & & 18 & 313 & 556 & $495,39 \pm 13,53$ & 850 & 3875 & $3008,33 \pm 175,65$ \\
\hline Sape & \multirow{2}{*}{ Apr-01 } & 14 & 320 & 575 & $432,14 \pm 19,87$ & 900 & 5300 & $2521,43 \pm 327,27$ \\
\hline Kupang & & 16 & 261 & 572 & $413,19 \pm 31,05$ & 500 & 4500 & $2155,00 \pm 362,06$ \\
\hline Sape & \multirow{2}{*}{ May-01 } & 16 & 290 & 640 & $504,69 \pm 23,25$ & 800 & 6300 & $3821,88 \pm 368,89$ \\
\hline Kupang & & 17 & 275 & 562 & $415,47 \pm 22,96$ & 550 & 4300 & $2105,88 \pm 304,26$ \\
\hline Sape & \multirow{2}{*}{ Jun-01 } & 14 & 240 & 620 & $373,21 \pm 33,67$ & 450 & 6100 & $1910,71 \pm 521,63$ \\
\hline Kupang & & 10 & 294 & 578 & $464,10 \pm 30,37$ & 600 & 5300 & $2875,00 \pm 525,60$ \\
\hline Sape & \multirow{2}{*}{ Jul-01 } & 13 & 240 & 480 & $374,62 \pm 19,99$ & 400 & 2800 & $1580,77 \pm 199,64$ \\
\hline Kupang & & 15 & 232 & 567 & $323,80 \pm 25,27$ & 400 & 4500 & $1163,33 \pm 290,71$ \\
\hline Sape & \multirow{2}{*}{ Aug-01 } & 13 & 270 & 603 & $436,54 \pm 28,78$ & 650 & 5450 & $2665,38 \pm 430,13$ \\
\hline Kupang & & 12 & 254 & 512 & $436,08 \pm 26,55$ & 500 & 3000 & $2187,50 \pm 272,90$ \\
\hline Sape & \multirow{2}{*}{ Sep-01 } & 6 & 354 & 526 & $441,17 \pm 26,20$ & 1000 & 3950 & $2425,00 \pm 402,23$ \\
\hline Kupang & & 17 & 299 & 622 & $448,47 \pm 25,93$ & 710 & 5900 & $2571,76 \pm 394,41$ \\
\hline Sape & \multirow{2}{*}{ Oct-01 } & 19 & 335 & 625 & $450,26 \pm 14,56$ & 1100 & 5830 & $2656,32 \pm 237,30$ \\
\hline Kupang & & 17 & 351 & 567 & $446,94 \pm 17,77$ & 1450 & 4500 & $2699,71 \pm 275,55$ \\
\hline Sape & \multirow{2}{*}{ Nov-01 } & 21 & 410 & 580 & $502,95 \pm 11,74$ & 2000 & 5550 & $3555,71 \pm 234,60$ \\
\hline Kupang & & 17 & 392 & 624 & $506,94 \pm 14,86$ & 1725 & 5650 & $3480,88 \pm 252,28$ \\
\hline Kupang & Dec-01 & 12 & 342 & 552 & $429,08 \pm 19,78$ & 1050 & 4250 & $2143,33 \pm 263,97$ \\
\hline \multicolumn{2}{|c|}{ TOTAL SAPE } & 167 & 240 & 640 & $434,71 \pm 7,07$ & 400 & 6300 & $2525,72 \pm 107,98$ \\
\hline \multicolumn{2}{|c|}{ TOTAL KUPANG } & 193 & 232 & 624 & $453,16 \pm 6,67$ & 400 & 5900 & $2595,98 \pm 87,36$ \\
\hline
\end{tabular}


dari 3 berarti ikan kakap merah ini mempunyai pertumbuhan yang bersifat alometrik negatip yaitu pertumbuhan panjang tidak seimbang dengan pertumbuhan beratnya. Berdasarkan jenis kelamin hubungan panjang berat di kedua lokasi tersebut juga mempunyai nilai $b<3$ (telah diuji dengan $t$ test). Dari Tabel 2 terlihat bahwa ikan yang berasal dari kedua lokasi tersebut mempunyai panjang dan berat maksimum yang relatif tidak berbeda. Di Sape panjang standar maksimum ikan betina $640 \mathrm{~mm}$ dengan berat 6.300 gram pada sampling bulan Mei 2001 dan di Kupang $622 \mathrm{~mm}$ dengan berat 5.900 gram pada bulan September 2001. Ukuran contoh ikan betina yang terkecil di Sape maupun di Kupang dengan berat 400 gram diperoleh pada bulan Juli 2001 (Tabel 3). Sedangkan untuk ikan jantan di Sape ukuran terkecil pada panjang $230 \mathrm{~mm}$ dan berat 370 gram serta yang terbesar ukuran panjang $690 \mathrm{~mm}$ mempunyai berat 8100 gram. Di Kupang ukuran jantan yang terkecil mempunyai panjang $242 \mathrm{~mm}$ dan berat 400 gram serta yang terbesar mempunyai panjang $704 \mathrm{~mm}$ dengan berat 7.750 gram. Deskripsi ikan jantan di Kupang dan di Sape selengkapnya dapat dilihat pada Tabel 4

Dalam sampling tersebut ditemukan juga ikan yang cukup besar ukurannya tetapi tidak bisa ditentukan jenis kelaminnya bahkan kadang tidak ditemukan gonadnya. Kondisi demikian ini dapat dilihat pada Tabel 5. Dalam pengamatan ini dibedakan antara ikan kakap merah yang berasal dari Sape dan Kupang karena menurut hasil penelitian genetik Sape dan Kupang berasal dari populasi (stock) yang berbeda (Salini, et al., 2003). Menurut Salini et al. (2003) ikan kakap merah yang berasal dari Bali, Lombok, dan Sumbawa (termasuk Sape) merupakan satu unit stock sedangkan Kupang, Tanimbar, Australia Timur, Kepulauan Aru, Arafura bagian Australia, Groote, dan Weipa merupakan satu unit stock yang lain.

Tabel 4. Rata-rata, kisaran panjany standard $(\mathrm{mm})$ dan berat $(\mathrm{g})$ ikan kakap merah jantan di Sape dan Kupang pada bulan Desember 2000 sampai dengan bulan Desember 2001

Table 4. The mean and range in length $(\mathrm{mm})$ and weight $(\mathrm{g})$ of male red snapper (L. malabaricus) collected from Sape between December 2000 and December 2001

\begin{tabular}{|c|c|c|c|c|c|c|c|c|}
\hline \multirow{2}{*}{ LOCATION } & \multirow{2}{*}{ MONTH } & \multicolumn{4}{|c|}{ Standard Length $(\mathrm{mm})$} & \multicolumn{3}{|c|}{ Weight (g) } \\
\hline & & $\mathrm{n}$ & Min & Max & Mean \pm SE & Min & Max & Mean $\pm S E$ \\
\hline Sape & Dec-00 & 13 & 289 & 377 & $341,23 \pm 7,03$ & 715 & 1500 & $1105,38 \pm 63,95$ \\
\hline Sape & \multirow{2}{*}{ Jan-01 } & 7 & 230 & 510 & $349,29 \pm 40,39$ & 370 & 3200 & $1357,14 \pm 387,94$ \\
\hline Kupang & & 11 & 478 & 565 & $539,73 \pm 8,77$ & 2750 & 4350 & $3715,91 \pm 141,63$ \\
\hline Sape & \multirow{2}{*}{ Feb-01 } & 12 & 310 & 589 & $396,75 \pm 21,29$ & 850 & 5000 & $1824,58 \pm 325,67$ \\
\hline Kupang & & 7 & 527 & 554 & $541,14 \pm 3,40$ & 3175 & 4000 & $3564,29 \pm 96,49$ \\
\hline Sape & \multirow{2}{*}{ Mar-01 } & 19 & 340 & 590 & $444,63 \pm 17,14$ & 1250 & 4750 & $2442,11 \pm 238,12$ \\
\hline Kupang & & 12 & 304 & 568 & $501,17 \pm 28,29$ & 775 & 4125 & $3259,17 \pm 362,91$ \\
\hline Sape & \multirow{2}{*}{ Apr-01 } & 2 & 370 & 615 & $492,50 \pm 122,50$ & 1500 & 6200 & $3850,00 \pm 2350,00$ \\
\hline Kupang & & 14 & 243 & 576 & $383,00 \pm 27,27$ & 500 & 5050 & $1828,57 \pm 349,48$ \\
\hline Sape & \multirow{2}{*}{ May-01 } & 8 & 240 & 690 & $492,50 \pm 56,15$ & 500 & 8100 & $4450,00 \pm 1092,51$ \\
\hline Kupang & & 6 & 293 & 623 & $394,00 \pm 51,92$ & 650 & 5300 & $1883,33 \pm 729,92$ \\
\hline Sape & \multirow{2}{*}{ Jun-01 } & 4 & 230 & 380 & $310,00 \pm 40,62$ & 400 & 2000 & $1212,50 \pm 402,27$ \\
\hline Kupang & & 13 & 242 & 573 & $389,77 \pm 36,52$ & 400 & 4450 & $1946,15 \pm 443,09$ \\
\hline Sape & \multirow{2}{*}{ Jul-01 } & 4 & 290 & 430 & $367,50 \pm 28,98$ & 900 & 1900 & $1400,00 \pm 208,17$ \\
\hline Kupang & & 9 & 264 & 413 & $318,78 \pm 14,46$ & 500 & 1850 & $875,56 \pm 131,71$ \\
\hline Sape & \multirow{2}{*}{ Aug-01 } & 17 & 280 & 490 & $401,88 \pm 16,17$ & 800 & 3800 & $2182,94 \pm 214,52$ \\
\hline Kupang & & 18 & 283 & 704 & $495,11 \pm 25,75$ & 550 & 7750 & $3280,56 \pm 404,67$ \\
\hline Sape & \multirow{2}{*}{ Sep-01 } & 24 & 321 & 618 & $462,92 \pm 15,73$ & 990 & 7200 & $2829,17 \pm 289,16$ \\
\hline Kupang & & 14 & 292 & 637 & $499,64 \pm 36,23$ & 710 & 6250 & $3644,29 \pm 567,88$ \\
\hline Sape & \multirow{2}{*}{ Oct-01 } & 8 & 335 & 510 & $443,13 \pm 19,91$ & 1150 & 3500 & $2357,50 \pm 259,89$ \\
\hline Kupang & & 13 & 382 & 595 & $484,85 \pm 17,12$ & 1600 & 5200 & $3080,00 \pm 302,12$ \\
\hline Sape & \multirow{2}{*}{ Nov-01 } & 3 & 430 & 620 & $511,33 \pm 56,53$ & 2040 & 6600 & $3946,67 \pm 1368,28$ \\
\hline Kupang & & 12 & 404 & 686 & $508,33 \pm 23,92$ & 1750 & 7300 & $3616,67 \pm 471,06$ \\
\hline Kupang & Dec-01 & 8 & 361 & 637 & $484,25 \pm 34,29$ & 1200 & 5550 & $3025,00 \pm 579,41$ \\
\hline \multicolumn{2}{|c|}{ TOTAL SAPE } & 121 & 230 & 690 & $419,39 \pm 8,49$ & 370 & 8100 & $2327,48 \pm 140,60$ \\
\hline \multicolumn{2}{|c|}{ TOTAL KUPANG } & 137 & 242 & 704 & $464,12 \pm 9,73$ & 400 & 7750 & $2866,61 \pm 139,21$ \\
\hline
\end{tabular}


Tabel 5. Rata-rata, kisaran panjang standard $(\mathrm{mm})$ dan berat $(\mathrm{g})$ ikan kakap merah yang tidak diketahui jenis kelaminnya di Sape dan Kupang pada bulan Desember 2000 sampai dengan bulan Desember 2001

Table 5. The mean and range in length $(\mathrm{mm})$ and weight $(\mathrm{g})$ of unidentified red snapper ( $L$. malabaricus) collected from Sape between December 2000 and December 2001

\begin{tabular}{|c|c|c|c|c|c|c|c|c|}
\hline \multirow{2}{*}{ LOCATION } & \multirow{2}{*}{ MONTH } & \multicolumn{4}{|c|}{ Standard Length $(\mathrm{mm})$} & \multicolumn{3}{|c|}{ Weight (g) } \\
\hline & & $n$ & Min & Max & Mean \pm SE & Min & Max & Mean $\pm S E$ \\
\hline$\overline{\text { Sape }}$ & Dec-00 & 1 & 371 & 371 & $371 \pm 0$ & 1450 & 1450 & $1450 \pm 0$ \\
\hline Sape & \multirow{2}{*}{ Jan-01 } & 16 & 220 & 440 & $293,44 \pm 14,37$ & 350 & 2500 & $838,75 \pm 132,69$ \\
\hline Kupang & & 0 & 0 & 0 & 0 & 0 & 0 & 0 \\
\hline Sape & \multirow{2}{*}{ Feb-01 } & 6 & 265 & 489 & $331,67 \pm 33,47$ & 560 & 3000 & $1188,33 \pm 375,14$ \\
\hline Kupang & & 0 & 0 & 0 & 0 & 0 & 0 & 0 \\
\hline Sape & \multirow{2}{*}{ Mar-01 } & 1 & 430 & 430 & $430 \pm 0$ & 2000 & 2000 & $2000 \pm 0$ \\
\hline Kupang & & 0 & 0 & 0 & 0 & 0 & 0 & 0 \\
\hline Sape & \multirow{2}{*}{ Apr-01 } & 0 & 0 & 0 & 0 & 0 & 0 & 0 \\
\hline Kupang & & 0 & 0 & 0 & 0 & 0 & 0 & 0 \\
\hline Sape & \multirow{2}{*}{ May-01 } & 6 & 240 & 610 & $419,17 \pm 61,97$ & 400 & 7500 & $3616,67 \pm 1301,13$ \\
\hline Kupang & & 2 & 421 & 442 & $431,50 \pm 10,50$ & 1750 & 2000 & $1875,00 \pm 125,00$ \\
\hline Sape & \multirow{2}{*}{ Jun-01 } & 22 & 240 & 680 & $322,77 \pm 23,50$ & 450 & 7000 & $1309,09 \pm 312,36$ \\
\hline Kupang & & 4 & 210 & 453 & $291,25 \pm 54,78$ & 300 & 2650 & $975,00 \pm 559,95$ \\
\hline Sape & \multirow{2}{*}{ Jul-01 } & 31 & 240 & 470 & $334,52 \pm 13,36$ & 400 & 2800 & $1148,39 \pm 115,53$ \\
\hline Kupang & & 8 & 225 & 367 & $290,25 \pm 16,51$ & 500 & 1100 & $712,50 \pm 83,32$ \\
\hline Sape & \multirow{2}{*}{ Aug-01 } & 9 & 255 & 452 & $322,22 \pm 22,79$ & 500 & 1950 & $994,44 \pm 197,98$ \\
\hline Kupang & & 0 & 0 & 0 & 0 & 0 & 0 & 0 \\
\hline Sape & \multirow{2}{*}{ Sep-01 } & 1 & 370 & 370 & $370 \pm 0$ & 700 & 700 & $700 \pm 0$ \\
\hline Kupang & & 0 & 0 & 0 & 0 & 0 & 0 & 0 \\
\hline Sape & \multirow{2}{*}{ Oct-01 } & 3 & 403 & 419 & $412,33 \pm 4,81$ & 1750 & 2100 & $1916,67 \pm 101,38$ \\
\hline Kupang & & 1 & 355 & 355 & $355 \pm 0$ & 1490 & 1490 & $1490 \pm 0$ \\
\hline Sape & \multirow{2}{*}{ Nov-01 } & 7 & 350 & 670 & $515,14 \pm 45,39$ & 2100 & 6540 & $3865,71 \pm 715,72$ \\
\hline Kupang & & 0 & 0 & 0 & 0 & 0 & 0 & 0 \\
\hline Kupang & Dec-01 & 2 & 421 & 484 & $452,50 \pm 31,50$ & 2050 & 2900 & $2475,00 \pm 425,00$ \\
\hline \multicolumn{2}{|c|}{ TOTAL SAPE } & 103 & 220 & 680 & $345,49 \pm 10,06$ & 350 & 7500 & $1481,17 \pm 145,72$ \\
\hline TOTAL K & PANG & 18 & 210 & 484 & $334,00 \pm 20,47$ & 300 & 2900 & $1199,44 \pm 191,78$ \\
\hline
\end{tabular}

\section{Tingkat Kematangan Gonad}

Dari pengamatan histologi diketahui bahwa ikan kakap merah (L. malabaricus) adalah "multiple spawner" dapat memijah beberapa kali dalam satu musim pemijahan hal ini terlihat pada gonad $L$. malabaricus bersifat "asynchronous" yaitu di dalam satu gonad terdapat beberapa tingkat kematangan (Gambar 2). Hal ini sejalan dengan penelitian Grimes, 1987 yang menyatakan bahwa ikan L. malabaricus seperti juga ikan lutjanids yang lain bersifat "serial spawner". Berdasarkan seluruh contoh gonad yang ada ukuran terkecil matang gonad ikan kakap merah ini adalah dengan panjang standar $420 \mathrm{~mm}$ dan berat 2 kg. Ikan kakap merah ini mulai terdapat gonad (tingkat I) pada ukuran panjang standar $240 \mathrm{~mm}$ dan berat 400 gram. Ukuran ini hampir sama dengan L.sebae yang dibudidayakan di Balai Besar Riset Perikanan Budidaya Laut Gondol pada panjang total $250 \mathrm{~mm}$ sudah mulai berkembang gonadnya (Suastika et. al., 2003). Penelitian Brouard dan Grandperrin (1984) di Vanuatu L. malabaricus matang gonad pada ukuran panjang $35 \mathrm{~cm}$.
Musim Pemijahan

Dari Tabel 6 dan Gambar 3 terlihat hampir setiap bulan terjadi pemijahan (tingkat VI) kecuali pada bulan Juli dan Desember baik di Kupang maupun di Sape.

Musim pemijahan kelihatannya hampir sepanjang tahun dengan dominasi pada bulan Januari, Februari, dan Maret. Menurut Grimes (1987) L. malabaricus di Andaman matang gonad pada bulan September dan puncak pemijahan terjadi pada bulan Nopember sampai dengan Januari.

\section{Fekunditas dan Diameter Oosit}

Menurut Grimes (1987) ikan kakap mencapai matang gonad pada saat $40-50 \%$ dari panjang maksimumnya. Untuk ukuran panjang $100 \mathrm{~cm}$ fekunditas mencapai 5-7 juta. Panjang total maksimum ikan kakap merah (L. malabaricus) 64,4 $\mathrm{cm}$ berasal dari Lamongan menurut Herianti \& Djamal (1993) sedangkan di Australia menurut Newman et al., (2000) panjang cagak maksimum dapat mencapai 

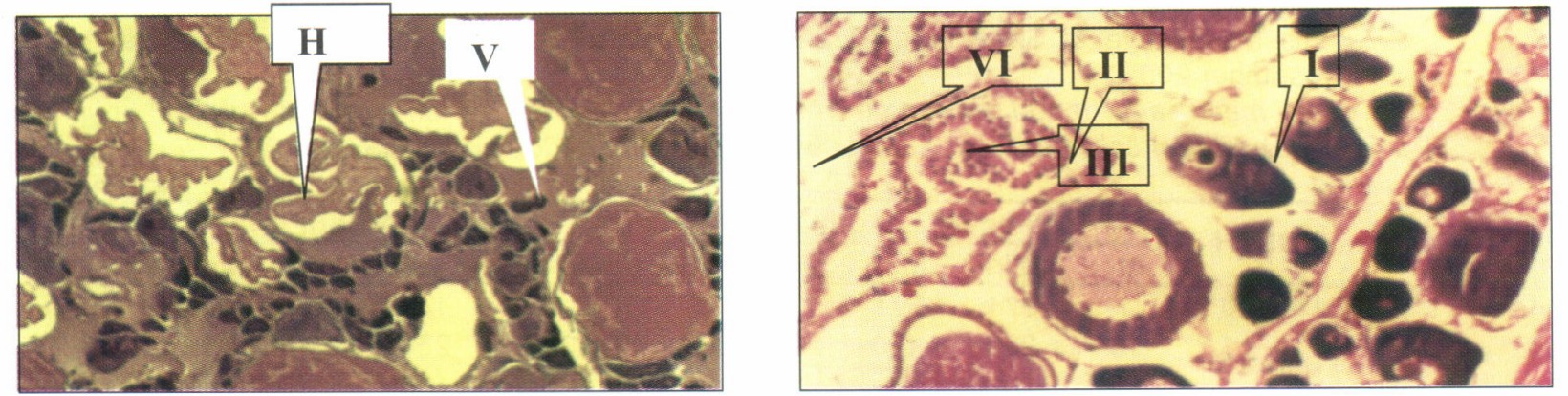

Gambar 2. Irisan gonad L. malabaricus dengan tingkat kematangannya (H\&E x 100).

Figure 2. Histological sections of the gonads of L. malabaricus showing the stages of maturity (H\&E $x$ 100).

Tabel 6. Distribusi bulanan tingkat kematangan gonad (\%) ikan kakap merah betina L. malabaricus dari perairan Sape dan Kupang pada bulan Desember 2000 sampai dengan Desember 2001

Table 6. Monthly distribution of maturity stages (\%) for female L. malabaricus from Sape and Kupang waters from December 2000 to December 2001

\begin{tabular}{|c|c|c|c|c|c|c|c|c|}
\hline \multirow{2}{*}{ LOCATION } & \multirow{2}{*}{ MONTH } & \multirow{2}{*}{$\mathrm{N}$} & \multicolumn{6}{|c|}{ Maturity Stage } \\
\hline & & & $\mathrm{I}$ & II & III & IV & $\mathrm{V}$ & $\mathrm{VI}$ \\
\hline Sape & Des-00 & 16 & - & 100 & - & - & - & - \\
\hline Sape & \multirow{2}{*}{ Jan-01 } & 9 & 11,11 & 44,44 & - & - & - & 44,44 \\
\hline Kupang & & 19 & - & - & 5,26 & 31,58 & 21,05 & 42,11 \\
\hline Sape & \multirow{2}{*}{ Feb-01 } & 15 & 6,67 & 20,00 & 13,33 & - & - & 60,00 \\
\hline Kupang & & 23 & - & - & - & 30,43 & 4,35 & 65,22 \\
\hline Sape & \multirow{2}{*}{ Mar-01 } & 12 & - & 58,33 & - & 8,33 & 16,67 & 16,67 \\
\hline Kupang & & 18 & - & 11,11 & - & - & 5,56 & 83,33 \\
\hline Sape & \multirow{2}{*}{ Apr-01 } & 14 & 7,14 & 35,71 & 7,14 & 35,71 & 7,14 & 7,14 \\
\hline Kupang & & 16 & 12,50 & 37,50 & 6,25 & 37,50 & - & 6,25 \\
\hline Sape & \multirow{2}{*}{ Mei-01 } & 16 & - & 31,25 & - & 12,50 & 43,75 & 12,50 \\
\hline Kupang & & 17 & 23,53 & 35,29 & - & - & 11,76 & 29,41 \\
\hline Sape & \multirow{2}{*}{ Jun-01 } & 13 & 53,85 & 30,77 & - & 7,69 & 7,69 & - \\
\hline Kupang & & 11 & 9,09 & 36,36 & - & 18,18 & - & 36,36 \\
\hline Sape & \multirow{2}{*}{ Jul-01 } & 13 & 69,23 & 30,77 & - & - & - & - \\
\hline Kupang & & 16 & 62,50 & 31,25 & - & 6,25 & - & - \\
\hline Sape & \multirow{2}{*}{ Agust-01 } & 13 & 7,69 & - & 46,15 & 15,38 & 23,08 & 7,69 \\
\hline Kupang & & 12 & 25,00 & 8,33 & - & 33,33 & 8,33 & 25,00 \\
\hline Sape & \multirow{2}{*}{ Sep-01 } & 6 & 16,67 & 16,67 & 16,67 & 16,67 & 16,67 & 16,67 \\
\hline Kupang & & 17 & 47,06 & 17,65 & - & 11,76 & 11,76 & 11,76 \\
\hline Sape & \multirow{2}{*}{ Okt-01 } & 21 & 14,29 & - & - & 33,33 & 9,52 & 42,86 \\
\hline Kupang & & 17 & 47,06 & 11,76 & 5,88 & 5,88 & 11,76 & 17,65 \\
\hline Sape & \multirow{2}{*}{ Nop-01 } & 21 & 19,05 & 23,81 & - & 57,14 & - & - \\
\hline Kupang & & 17 & 23,53 & - & 5,88 & 47,06 & - & 23,53 \\
\hline Kupang & Des-01 & 11 & 81,82 & - & 18,18 & - & - & - \\
\hline \multicolumn{2}{|c|}{ TOTAL SAPE } & 169 & 16,57 & 31,95 & 5,92 & 18,34 & 10,06 & 17,16 \\
\hline \multicolumn{2}{|c|}{ TOTAL KUPANG } & 194 & 25,26 & 14,95 & 3,09 & 19,07 & 6,70 & 30,93 \\
\hline
\end{tabular}

$705 \mathrm{~mm}$. Di Kupang dan di Sape ikan kakap merah matang gonad pada panjang standar $413 \mathrm{~mm}$ dan jumlah telurnya (fekunditas) dapat dilihat pada Tabel 7. Di Kupang panjang standar $465 \mathrm{~mm}$ mempunyai fekunditas 54.618 butir (Tabel 8). Fekunditas rata-rata ikan kakap merah di Kupang dan di Sape disajikan pada Tabel 9.
Hubungan antara panjang standar dan fekunditas (Gambar 4 dan 5) serta fekunditas dengan berat (Gambar 6 dan 7) terlihat bahwa sepertinya tidak ada hubungan yang erat antara fekunditas dan ukuran panjang ikan serta beratnya baik di Kupang maupun di Sape. Untuk melihat hubungan ini telah dicoba dengan membuat regresi antara keduanya ternyata 


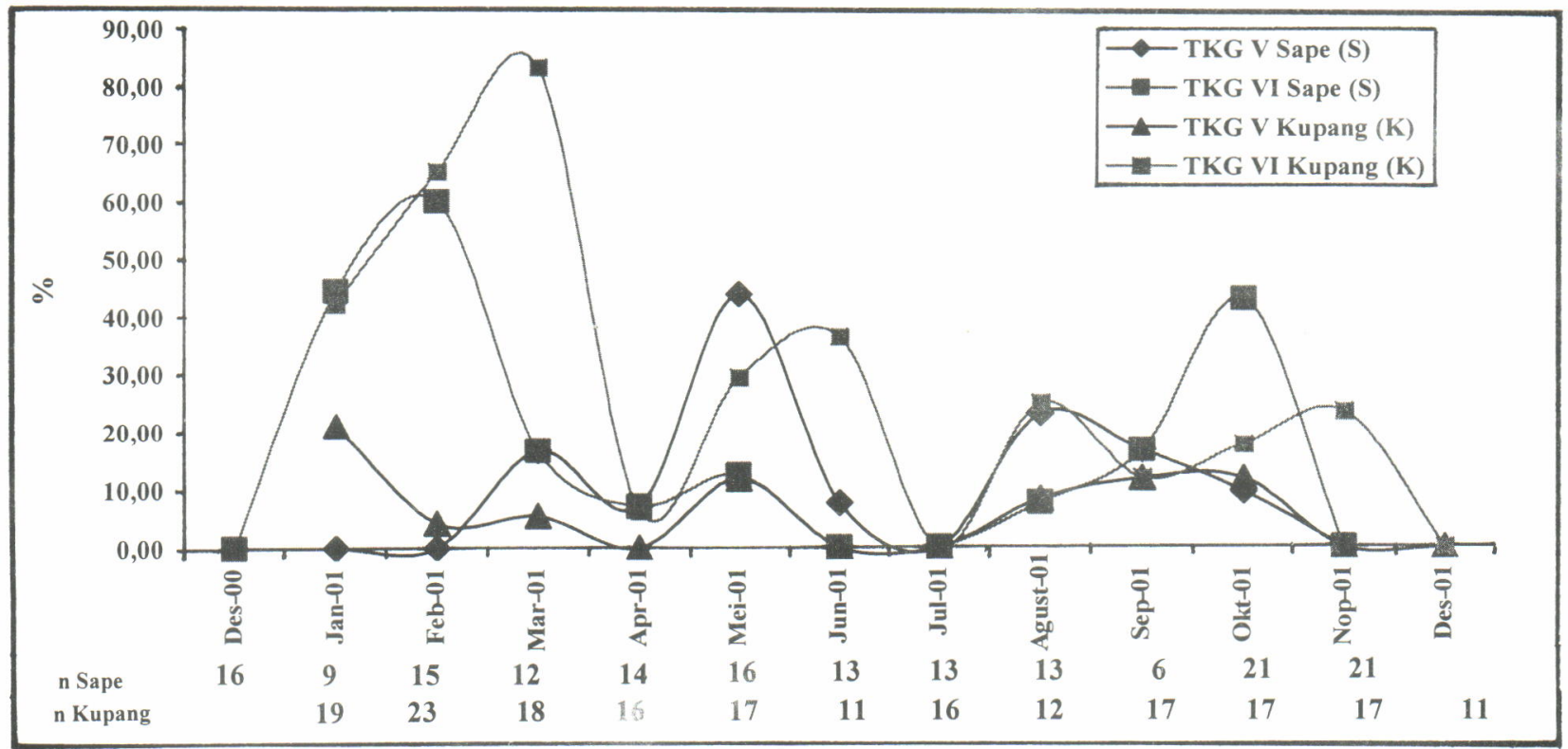

Gambar 3. Persentase ikan kakap merah (L. malabaricus) tingkat V (reproduksi), dan tingkat VI (salin) dari Sape dan Kupang.

Figure 3. The percentage of each gonad stage V (running ripe) and VI (spent) L. malabaricus from Sape and Kupang.

Tabel 7. Fekunditas ikan kakap merah (L. malabaricus) dari Sape $(n=26)$

Table 7. Fecundity of red snapper (L. malabaricus) from Sape $(n=26)$

\begin{tabular}{|c|c|c|c|}
\hline Tanggal/Date & $\mathrm{SL}(\mathrm{mm})$ & $W(g)$ & Fecundity \\
\hline 05-Feb-01 & 540 & 3.550 & 72.666 \\
\hline 05-Feb-01 & 540 & 3.600 & 53.764 \\
\hline 05-Feb-01 & 580 & 4.800 & 59.193 \\
\hline 05-Feb-01 & 600 & 5.050 & 83.433 \\
\hline 22-Mar-01 & 431 & 2.000 & 165.603 \\
\hline 22-Mar-01 & 471 & 3.800 & 441.407 \\
\hline 21-Apr-01 & 575 & 5.300 & 575.625 \\
\hline 22-Apr-01 & 495 & 3.300 & 587.100 \\
\hline 22-Mei-01 & 510 & 3.500 & 137.418 \\
\hline 27-Mei-01 & 520 & 3.800 & 29.100 \\
\hline 27-Mei-01 & 530 & 5.500 & 387.899 \\
\hline 17-Jun-01 & 550 & 4.500 & 643.366 \\
\hline 17-Jun-01 & 620 & 5.700 & 293.576 \\
\hline 23-Agust-01 & 527 & 4.250 & 302.105 \\
\hline 28-Agust-01 & 571 & 5.250 & 361.545 \\
\hline 30-Agust-01 & 413 & 2.250 & 293.878 \\
\hline 30-Agust-01 & 450 & 2.400 & 175.950 \\
\hline 19-Sep-01 & 526 & 3.950 & 346.068 \\
\hline 06-Okt-01 & 520 & 3.200 & 275.553 \\
\hline 21-Okt-01 & 460 & 2.750 & 360.765 \\
\hline 21-Okt-01 & 460 & 3.530 & 369.976 \\
\hline 21-Okt-01 & 465 & 2.900 & 453.048 \\
\hline 21-Okt-01 & 470 & 2.800 & 429.030 \\
\hline 21-Okt-01 & 500 & 3.250 & 404.746 \\
\hline 21-Okt-01 & 500 & 3.250 & 434.151 \\
\hline 21-Okt-01 & 500 & 3.300 & 489.468 \\
\hline
\end{tabular}


baik secara exponensial maupun linear mempunyai nilai koefisien korelasi yang sangat kecil ( $r=0,05-$ 0,15). Ikan yang berukuran besar tidak selalu mempunyai fekunditas yang lebih banyak. Diameter oosit L. malabaricus di Kupang maupun di Sape kurang lebih berukuran $500-600 \mu$ (tingkat V).
Diameter oosit L. malabaricus jauh lebih kecil bila dibandingkan dengan dimater oosit $L$. sebae $(950 \mu)$ dan L. argentimaculatus $(870 \mu)$ yang memijah di Balai Besar Riset Perikanan Budidaya Laut Gondol (Suastika et al., 2003)

Tabel 8. Fekunditas ikan kakap merah (L. malabaricus) dari Kupang $(n=34)$

Table 8. Fecundity of red snapper (L. malabaricus) from Kupang $(n=34)$

\begin{tabular}{|c|c|c|c|}
\hline Date & $\mathrm{SL}(\mathrm{mm})$ & $W(g)$ & Fecundity \\
\hline 07-Des-00 & 473 & 2.800 & 852.979 \\
\hline 18-Jan-01 & 473 & 2.850 & 438.948 \\
\hline 18-Jan-01 & 482 & 3.250 & 862.674 \\
\hline 18-Jan-01 & 492 & 3.150 & 578.149 \\
\hline 18-Jan-01 & 498 & 3.275 & 520.447 \\
\hline 18-Jan-01 & 503 & 3.260 & 272.893 \\
\hline 18-Jan-01 & 504 & 3.150 & 605.245 \\
\hline 18-Jan-01 & 512 & 3.200 & 258.308 \\
\hline 18ss-Jan-01 & 522 & 3.350 & 632.890 \\
\hline 18-Jan-01 & 532 & 3.550 & 511.427 \\
\hline 18-Jan-01 & 536 & 3.350 & 435.124 \\
\hline 02-Feb-01 & 492 & 3.000 & 514.208 \\
\hline 02-Feb-01 & 496 & 2.750 & 253.852 \\
\hline 02-Feb-01 & 501 & 3.000 & 208.706 \\
\hline 21-Feb-01 & 513 & 3.250 & 438.044 \\
\hline 21-Feb-01 & 563 & 4.025 & 169.817 \\
\hline 25-Feb-01 & 494 & 3.000 & 202.471 \\
\hline 25-Feb-01 & 515 & 3.400 & 530.246 \\
\hline 25-Feb-01 & 525 & 3.525 & 336.729 \\
\hline 19-Apr-01 & 533 & 3.800 & 252.071 \\
\hline 24-Apr-01 & 496 & 2.925 & 651.420 \\
\hline 24-Apr-01 & 521 & 3.200 & 179.258 \\
\hline 24-Apr-01 & 527 & 3.225 & 333.288 \\
\hline 24-Apr-01 & 545 & 3.650 & 318.279 \\
\hline 24-Apr-01 & 572 & 4.075 & 518.977 \\
\hline 19-Mei-01 & 465 & 2.700 & 54.618 \\
\hline 19-Mei-01 & 526 & 4.050 & 587.743 \\
\hline 27-Jun-01 & 578 & 5.300 & 624.116 \\
\hline 15-Jul-01 & 567 & 4.500 & 848.948 \\
\hline 16 -Agust-01 & 496 & 3.000 & 303.788 \\
\hline 20-Sep-01 & 572 & 4.400 & 200.760 \\
\hline 24-Sep-01 & 473 & 3.100 & 168.060 \\
\hline 29-Sep-01 & 551 & 4.600 & 517.095 \\
\hline 19-Okt-01 & 522 & 3.725 & 204.838 \\
\hline
\end{tabular}

Tabel 9.

Table 9 .

Fekunditas rata-rata ikan kakap merah (L. malabaricus) dari Sape dan Kupang Mean batch fecundity of red snapper (L. malabaricus) from Sape and Kupang

\begin{tabular}{ccccc}
\hline Site & Minimum & Maksimum & Mean \pm SE & N \\
\hline Sape & 29,100 & 643,366 & $316,401 \pm 33,698$ & 26 \\
Kupang & 54,618 & 862,674 & $423,130 \pm 36,027$ & 34 \\
\hline
\end{tabular}




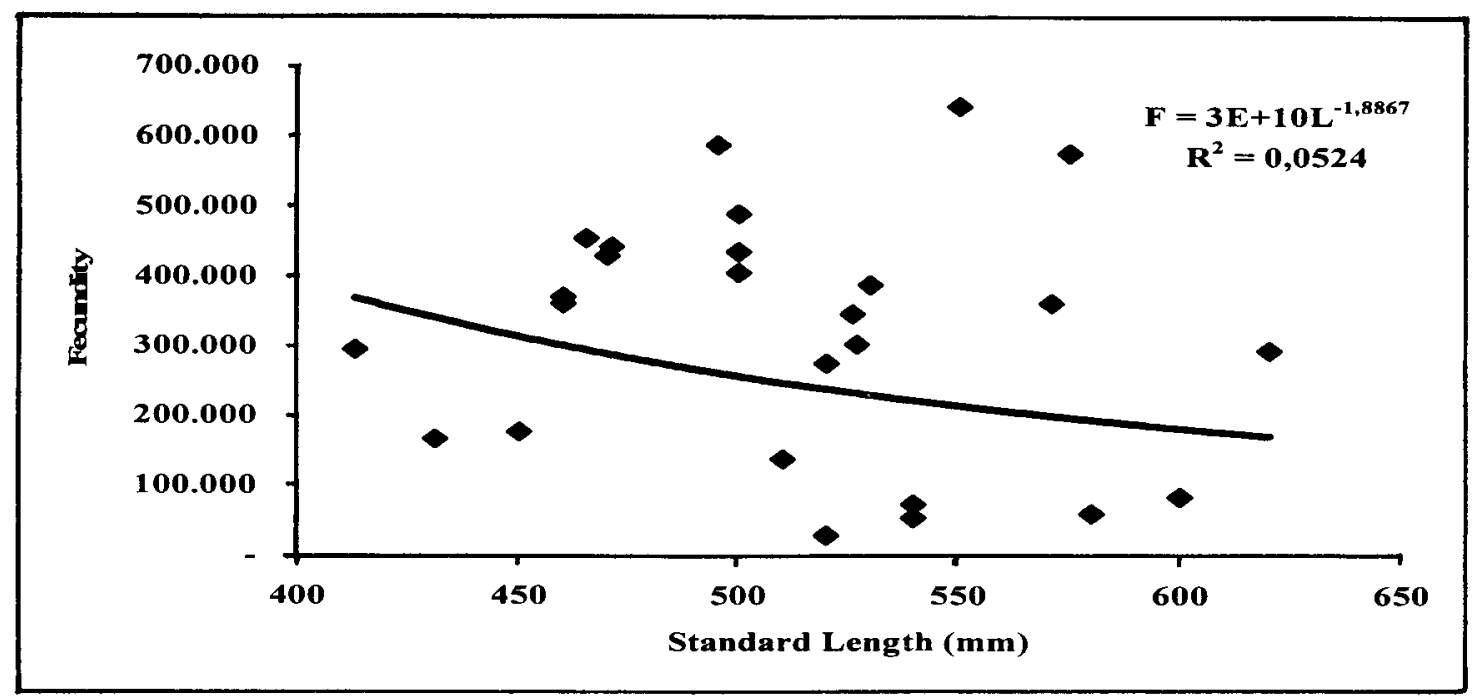

Gambar 4. Hubungan antara panjang dan fekunditas ikan kakap merah (L. malabaricus) di Sape $(n=26)$. Figure 4. Relationship between batch fecundity and length of $L$. malabaricus from Sape $(n=26)$.

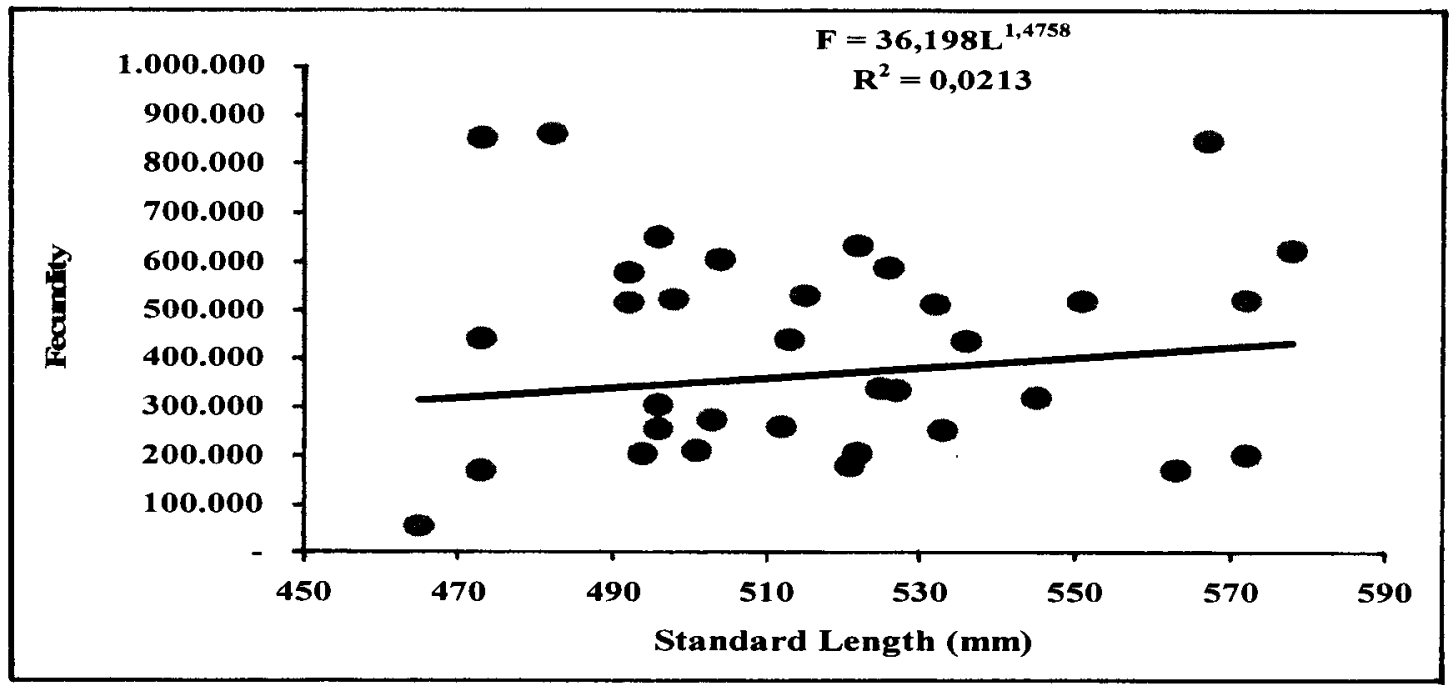

Gambar 5 Figure 5.
Hubungan antara panjang dan fekunditas ikan kakap merah (L. malabaricus) di Kupang $(n=34)$. Relationship between batch fecundity and length of $L$. malabaricus from Kupang ( $n=34$ ). 


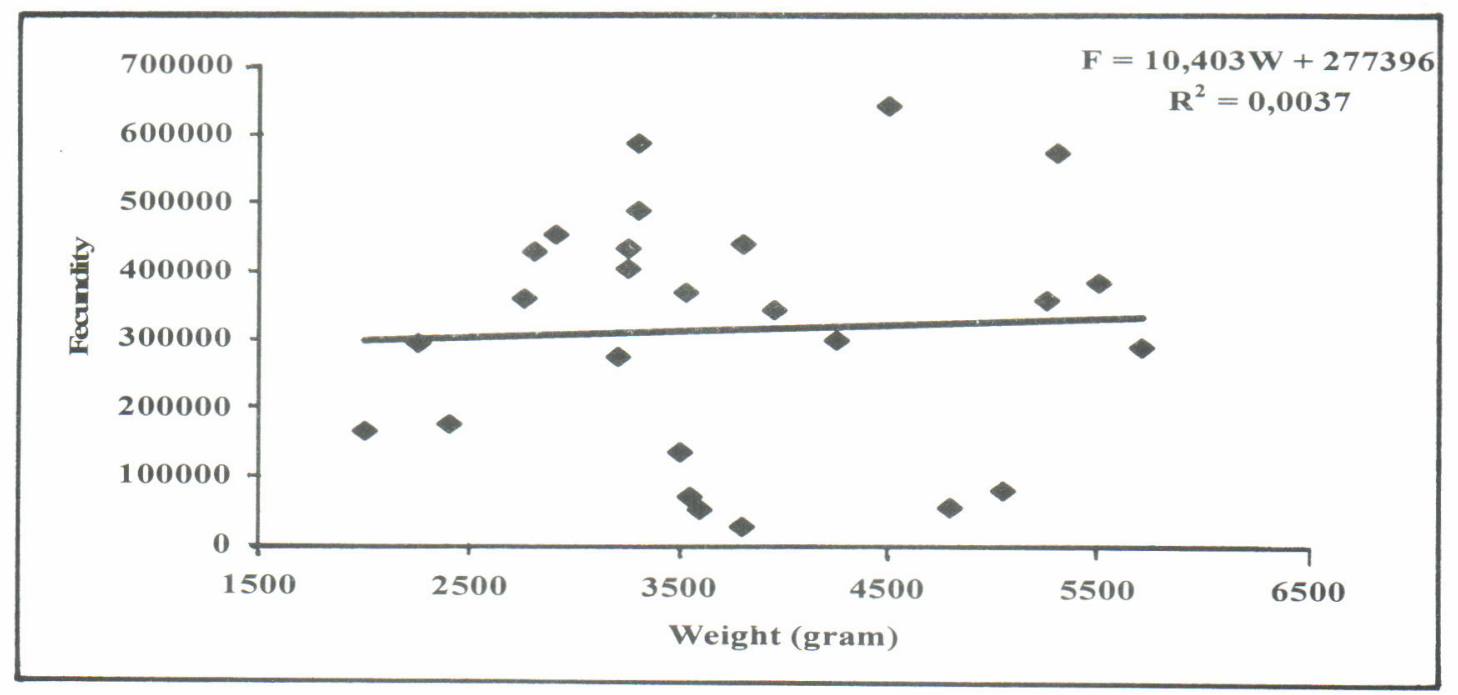

Gambar 6 Hubungan antara berat dan fekunditas ikan kakap merah (L. malabaricus) di Sape $(n=26)$. Figure 6. Relationship between batch fecundity and weight of L. malabaricus from Sape $(n=26)$.

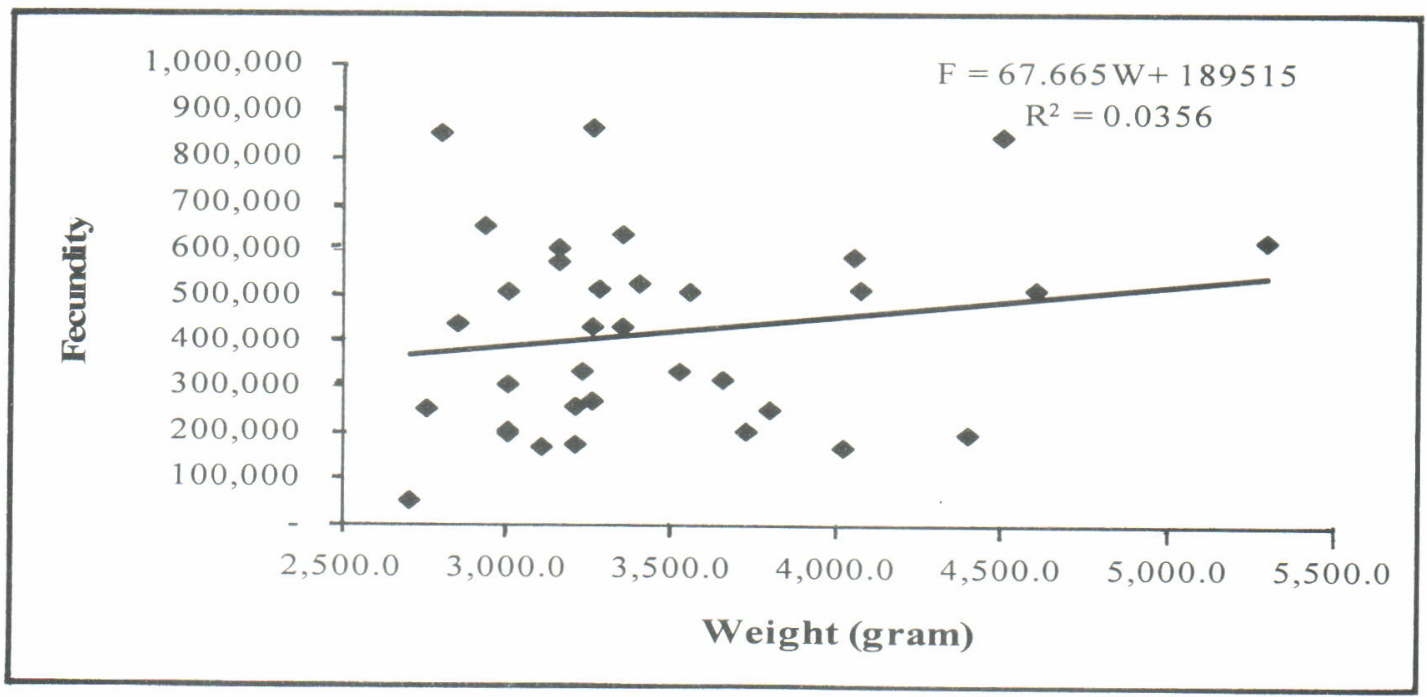

Gambar 7. Hubungan antara panjang dan fekunditas ikan kakap merah (L. malabaricus) di Kupang ( $\mathrm{n=34}$ ) Figure 7. Relationship between batch fecundity and length of L. malabaricus from Kupang ( $n=34)$.

\section{KESIMPULAN}

1. Ikan kakap merah L. malabaricus yang berasal dari perairan Sape dan Kupang berdasarkan uji t mempunyai hubungan panjang-berat yang bersifat alometrik negatip $(b<3)$.

2. Tidak ada hubungan yang erat antara panjang, berat, dan fekunditas ( $r=0,05$ sampai 0,17$)$. Fekunditas rata-rata di Sape 316.401 butir sedangkan di Kupang 423.130 butir. Diameter oosit berkisar antara 500-600 $\mathrm{m}$ untuk tingkat $\mathrm{V}$ baik di Kupang maupun di Sape.
3. Pemijahan diduga berlangsung sepanjang tahun dengan puncak musim pemijahan antara bulan Januari sampai dengan Maret.

\section{UCAPAN TERIMA KASIH}

Ucapan terima kasih disampaikan kepada Sdr. Mujimin yang telah membuat preparat histologi dan Sdr. Bambang Teguh Trihandoyo dalam penyiapan grafik. Penelitian ini merupakan bagian dari penelitian kerja sama antara pemerintah Indonesia dan Australia (ACIAR Project FIS/97/165). 


\section{DAFTAR PUSTAKA}

Allen, G.R. 1985. Snappers of the world. An annotated and illustrated catalogue of lutjanid species known to date. FAO species catalogue. Vol. 6.

Andamari, R., M. Farmer, U. Khodriyah, \& AN Susanto. 1998. Gonad maturity stages of anchovies (Encrasicholina heterolobus) from Bacan. Island. Indonesian Fisheries Research Journal. Vol. IV No. 2: 47-51.

Bagenal, T.B. 1978. Methods for assessment of fish production in fresh water. IBP Handbook (3). Blackwell Scientific Publications, Oxford. 253 pp.

Brouard, F. \& R. Granperrien. 1984. Less poisons profonds de la pinta recifale externa a Vanuatu. ORSTOM, Notes Doc. D'Oceanogr. 11:71-79.

Effendie, M.I. 1997. Biologi Perikanan. Yayasan Pustaka Nusatama. Yogyakarta.

Grimes, C.B. 1987. Reproductive biology of the Lutjanidae: A Review. Westview Press. Boulder and London. Pp.: 239-294.

Herianti, I \& R. Djamal. 1993. Dinamika populasi kakap merah (Lutjanus malabaricus) (Bloch and Schneider) di perairan Utara Laut Jawa. Jurnal Penelitian Perikanan Laut No. 78: 18-25.

Luna, L.G. 1968. Manual of histological staining methods of the Arm Forces. Third ed. Institute of pathology. McGraw-Hill, New York.

McPaerson, G.R., Squire, L. \& O'Brien, J. 1992. Reproduction of three dominant Lutjanus species of the Great Barrier Reef Inter-Reef fishery. Asian Fish. Sci. 5: 25-36.

Milton, D.A. \& Blaber, S.J.M. 1991. Maturation, spawning seasonality and proximate spawning stimuli of six species of tuna baitfish in the Solomon Islands. Fish. Bull. U.S. 89: 221-237.

Newman, S.J., M. Cappo \& D. Williams. 2000. Age, growth, mortality rates, and corresponding yield estimates using otoliths of the tropical red snappers, Lutjanus erythropterus, L. malabaricus, and $L$. sebae, from the central Great Barrrier Reef. Fisheries Research 48: 1-14.

Royce, W.F. 1984. Introduction to the practice of fishery science. Academic Press, California, USA. $423 \mathrm{pp}$.

Salini, J., K. Sugama, Haryanti, S.B. Moria, \& J. Ovenden. 2003. Population genetics of snappers using mDNA methods. Final Coordination Meeting Perth, 2003.

Sainsbury K.J, P.J. Kailola \& G.G. Leyland.1985. Continental Shelf Fishes of Northern and NorthWestern Australia. An Illustrated Guide. CSIRO Division Of Fisheries Research. Canberra, Australia.

Suastika, M., P.I. Imanto, \& A. Priyono. 2003. Catatan aspek biologi pemeliharaan induk ikan kakap merah di Balai Besar Riset Perikanan Gondol, Bali. 2003 (belum diterbitkan).

Suboko, B. 1997. Indonesian fisheries industry needs and opportunities. Paper presented to the AsiaPacific Fishing Conference and Exhibition, Cairns, Australia, 7-10 July 1997. Indonesian Fisheries Federation. Pp. 19. 
